\title{
EDUCACIÓN
}

\section{Gobernanza de la educación superior. El rol del aseguramiento de la calidad. Los casos de Argentina y Chile}

\author{
María del Rocío Robledo Y. ${ }^{1}$
}

\begin{abstract}
Resumen
Introducción: En la década del 90, los organismos internacionales como el Banco Mundial (BM) y el Banco Interamericano de Desarrollo (BID), prescribieron políticas económicas, buscando impacto social y político en los países de América Latina, entre las cuales aparece la educación superior como agente para el desarrollo económico y social, lo cual fue apoyado con financiamiento de estos organismos a las reformas del sector. En este contexto, se conforma una nueva agenda para el debate de la educación superior, que hace relación con el rol del Estado y la autonomía institucional, la rendición de cuentas y las demandas de información pública y los nuevos actores de la educación superior, todo ello en un marco de libertades sociopolíticas e intelectuales, que buscan precautelar la confianza social en la educación superior y favorecer la gobernabilidad del sistema, con demandas de contribución al desarrollo económico y social de los países (Banco Mundial, 2000). El enfoque economicista de estas medidas es contestado por UNESCO y CEPAL, con una aproximación más humanista. El sustento de una articulación efectiva entre el Estado y la sociedad se construye sobre la base de acuerdos entre los gobernantes y una mayoría representativa de la sociedad afectada, es por ello que las constituciones de América Latina hacen responsable al Estado de garantizar el acceso y la calidad de la educación como derecho consagrado.
\end{abstract}

Objetivos: El objetivo general del estudio es el de analizar las agencias de aseguramiento de la calidad de la educación superior de Argentina y Chile como instrumento de política pública en su contribución a la gobernanza de la educación superior. En el estudio se parte del contexto político, social y económico en el que se han desarrollado los sistemas de educación superior en los dos países seleccionados, Argentina y Chile, en las dos últimas décadas, analizando los sistemas de la educación superior en los dos países, desde su tradición e historia, sus particularidades, los procesos de reforma y el enfoque de las políticas públicas que dieron origen a los sistemas de aseguramiento de la calidad, considerando a las agencias como entes reguladores y su articulación política y social con los actores de la educación superior, como agentes de gobernanza de los sistemas de educación superior.

1. Centro para el Desarrollo de la Competitividad, CDC., Paraguay.

E-mail: robledo@cdc.com.py

DOI: 10.26885/rcei.foro.2017.67 
Material y Método: Para el estudio se ha empleado la metodología cualitativa, empleando el método naturalista, utilizando el estudio de caso holístico, múltiple (Tipo3, descriptivo ilustrativo (Díaz de Salas, Mendoza Martínez, \& Porras Morales, 2011; Yin, 2013). Los casos han sido seleccionados porque son los que cuentan con mayor desarrollo en términos de aseguramiento de la calidad de la educación universitaria, en la región sur de Sudamérica, con tres décadas de funcionamiento para Chile y dos décadas para la Argentina. Se han planteado dos matrices para el estudio, la primera es una matriz de dimensiones de análisis para el contexto de la investigación previa al desarrollo del estudio. La segunda matriz parte de la definición de los Indicadores Mundiales de Gobernabilidad, IGM, del Banco Mundial, BM, a fin de analizar la acción de las agencias como agentes de gobernabilidad para el sistema de educación superior (Banco Mundial \& Brookings Institution, 2013), en función de documentos del BM que establecen el aseguramiento de la calidad como elemento relevante para garantizar la gobernabilidad.

Partiendo del análisis documental de referencias sobre el tema, se realizaron entrevistas a profundidad a expertos reconocidos en el tema ( 6 en Argentina y 8 en Chile). Los instrumentos han constado de una guía de análisis documental y cuestionario de entrevistas a expertos.

Resultados y Conclusiones: El aseguramiento de la calidad tiene su utilidad para la regulación de la educación superior, la información pública y la mejora continua. Luego de aplicar estas políticas, la pregunta a realizar es qué se hace después, cómo se continúa (Salazar \& Leihy, 2013). En este escenario cabría girar la mirada hacia las experiencias de otros países, tal como se realizó en el inicio del proceso. Es posible que sea necesario trascender a otra fase, tal como en el caso holandés y su Modelo de Fases (Jeliazkova \& Westerheijden, 2002), revisando las cuestiones básicas de la autorregulación y la mejora continua, como parte esencial del ethos universitario. Es posible también observar diversas instancias de acuerdo al nivel de análisis, tal como hoy día se cuenta para la docencia y la investigación, pensando en la articulación de los niveles, la transferencia de los créditos de los programas internacionales, la formación continua, e incluso la auto formación, en plataformas de educación virtual. La cierto es que la educación superior debe hoy ser mirada como un bien público, un derecho, variada en niveles, tipologías, enfoques, heterogénea y, aun así, de calidad, precautelando los intereses de la sociedad, que ve en ella la formación de las personas que definen con sus acciones el desarrollo de un país. Con esa configuración, ya no resulta adecuada la idea de órganos de regulación únicos con procedimientos normados para una tipología uniforme. En las condiciones actuales, estos sistemas serán profundamente modificados por las nuevas legislaciones en proceso y esa transformación se vislumbra controversial tal como lo fue, en su momento, aquella que dio origen a los sistemas de aseguramiento de la calidad en los casos analizados en este trabajo. 
Palabras clave: gobernanza, gobernabilidad, aseguramiento de la calidad, política pública, educación superior, agencias de evaluación.

\section{Referencias}

Banco Mundial \& Brookings Institution. (2013). Indicadores mundiales de gobernabilidad. Recuperado de http://web.worldbank.org/: http:// go.worldbank.org/P5OPS6CLI0

Banco Mundial. (29 de 02 de 2000). Higher education in developing countries : peril and promise. Recuperado de http://documentos.bancomundial.org/curated/ es/2000/02/437224/higher-education-developing-countries-peril-promise

CINDA-UNIVERSIA. (2012). Aseguramiento de la calidad en Iberoamérica. En M. J. Lemaitre \& M. E. Zenteno (Eds.), Educación Superior. Santiago de Chile: RIL.

Jeliazkova, M. \& Westerheijden, D. F. (2002). Systemic adaptation to a changing environment: Towards a next generation of quality assurance models. Higher Education, (44), 433-448. 